\title{
Novel Method of ACO and Its Application to Rotor Position Estimation in a SRM under Normal and Faulty Conditions
}

\author{
Hossein Torkaman ${ }^{\dagger}$, Ebrahim Afjei*, Hossein Babaee**, and Peyman Yadegari* \\ $\dagger^{*}$ Department of Electrical Engineering, Shahid Beheshti University, G.C., Tehran, Iran \\ ** Department of Electrical Engineering, Babol Noshirvani University of Technology, Babol, Iran
}

\begin{abstract}
In this paper a novel method of the Ant Colony Optimization algorithm for rotor position estimation in Switched Reluctance Motors is presented. The data provided by the initial assumptions is one of the important aspects used to solve the problems relative to an Ant Colony algorithm. Considering the nature of a real ant colony, it was found that the ants have no primary data for deducing which is the shortest path in their initial iteration. They also do not have the ability to see the food sources at a distance. According to this point of view, a novel method is presented in which the rotor pole position relative to the corresponding stator pole in a switched reluctance motor is estimated with high accuracy using the active and inactive phase parameters. This new method gives acceptable results such as a desirable convergence together with an optimized and stable response. To the best knowledge of the authors, such an analysis has not been carried out previously.
\end{abstract}

Key Words: Ant Colony Optimization (ACO), Fault Control, Rotor Position Estimation, Switched Reluctance Motor (SRM)

\section{INTRODUCTION}

Swarm Intelligence (SI) has recently attracted the attention of many scientists. Swarm Intelligence tries to model the complicated behavior of social insect that live in large groups and work with each other [1]-[3]. The outstanding feature of these groups of insects is that, although they are not complicated creatures and do not have complicated brains, they have the ability to overcome all of their daily life obstacles without having complete data from their surroundings [4]-[6]. These models are providing solutions to scientific problems mostly in engineering fields [7]. Algorithms that are optimized and implemented based on the abilities of ants, play a large role in swarm intelligence science. The most famous of these algorithms is known as ACO or simply Ant Colony Optimization.

On the other hand, the salient features of a Switched Reluctance Motor (SRM) such as the lack of a coil or a permanent magnet on the rotor, a simple structure and high reliability [8]-[13], makes it a suitable candidate for operation in harsh or sensitive applications [14]-[18].

Although SRMs have unique characteristics, they require ro-

Manuscript received Aug. 18, 2010; revised Sep. 9, 2011

Recommended for publication by Associate Editor Jang-Mok Kim.

$\dagger$ Corresponding Author: H_Torkaman@sbu.ac.ir

Tel: +982129904107, Shahid Beheshti University

* Dept. of Electrical Engineering, Shahid Beheshti University, Iran

** Dept. of Electrical Engineering, Babol Noshirvani University of Technology, Iran. tor position estimation to achieve proper operation of the motor [19]. In this context, there are direct and indirect methods for extracting rotor position information. In the direct methods the control is based on using discrete sensors on the back of motor, while in indirect motor control these sensors have been eliminated [20]-[22]. Some of the popular methods for indirect rotor position detections are: the Sensor Elimination technique based on current waveform detection using impedance sensing, the Amplitude Modulation technique, the Frequency and Phase technique, Mutual Induced Voltage measurement, the Resonance technique, methods based on an observer, etc [23][26]. In this paper a new method is presented for rotor position estimation as a part of motor control in different modes.

This paper is organized as follow: The Ant Colony Algorithm is introduced in the second section and optimization is considered in the third section. An enhanced Ant Colony Algorithm with its flowchart and the steps required for implementation are presented in the fourth section. The proposed method of rotor position detection in SRMs is implemented and the results are given and analyzed in the fifth section. Concluding remarks are presented in the sixth section.

\section{ACO Algorithm Evaluation}

ACO is method for solving optimization problems which was inspired from nature based on a real ant colony [27]. Real ants are able to find the shortest path using only the pheromone trails deposited by other ants. 
The reasons for using a ACO algorithm for solving the Traveling Salesman Problem (TSP) are; a) this problem is so complicated that no polynomial algorithm can used for it. b) pheromone evaporation is used as a negative feedback in this algorithm in order to avoid early convergence.

In addition, ACO has a major advantage over other methods. All of the other methods only find the shortest path and if one of the paths is eliminated, the problem must be solved again from the beginning. After the elimination of a path using ACO, a route can be found which has less pheromone when compared to the former path, and more pheromone when compared to all of the other paths. Therefore, it is not necessary to solve the problem all over again.

In this algorithm $n$ points should be connected to each other when facing the TSP, and the beginning and final points must be essentially the same, and they must also be minimized through travel [28]-[31]. In the preceding part the distance $\left(d_{i, j}\right)$ between the city $i\left(x_{i}, y_{i}\right)$ and the city $j\left(x_{j}, y_{j}\right)$, in Euclidean space, is calculated using the following equation:

$$
d_{i, j}=\left[\left(x_{i}-x_{j}\right)^{2}+\left(y_{i}-y_{j}\right)^{2}\right]^{\frac{1}{2}} .
$$

In the resolving procedure the ants make their tour by traveling on the graph so that they pass the cities one by one until their tour is finished. This means that they have passed all of the cities. The city selection is examined when in the city $i$ using the locally visible data.

$$
\eta_{i, j}=\frac{1}{d_{i, j}}
$$

where; $d_{i, j}$ is the distance between the cities $i$ and $j$ in Euclidean space. $\eta_{i, j}$ is called visibility, which is strictly local information and represents the heuristic desirability of choosing city $j$ when in city $i$.

The pheromone deposits, $\tau_{i, j}$ on the edge connect city $i$ to city $j$, which represent the learned desirability of choosing city $j$ when in city $i$.

The transition rule or $\rho(t)$ is the probability of selecting the $k^{\text {th }}$ ant that wants to travel from the city $i$ while making its tour of city $t$.

$$
\rho_{i j}^{k}(t)=\frac{\left[\tau_{i j}(t)\right]^{\alpha} \cdot\left[\eta_{i j}\right]^{\beta}}{\sum_{l \in S_{i}^{k}}\left[\tau_{i l}(t)\right]^{\alpha} \cdot\left[\eta_{i l}\right]^{\beta}} \quad \text { if } j \in S_{i}^{k}
$$

where; $\alpha, \beta$ are constants.

When $\alpha=0$, there is no cooperation, this is a greedy search with multiple starting points.

When $\beta=0$, there is no preference for the shortest edge which leads to sub-optimality.

$S_{i}^{k}$ is the Tabu list for ant $k$ when it is located in city $i$, which contains not-visited cities (at the beginning it contains all of the cities). When the tour is complete and all of the ants have made one complete iteration, each ant trail has $k$ amount of pheromone on the edge $i, j$ and the ant in its new tour, selects the routes that have better transition rules and greater visibility. It reaches the shortest path for traveling in this way.

\section{PRoblem STATEMENT}

Although there is no need for a biological excuse to reach an engineering solution, an optimized and applicable method should be used. For example, in the TSP the data related to the solution of the problem like locations, distances between cities, etc. must be given to achieve an optimized solution using the ACO algorithm.

Therefore, it is required that the algorithm achieve the data using repetition and learning, which are the result of data from swarm intelligence and self organization. In the ACO algorithm, it is assumed that an ant has a kind of initial visibility which can estimate the distance from nearby cities as in the TSP. These static data will be useless in dynamic problems unless the ants are given a kind of memory regarding its surroundings.

This paper presents a method that gives the ants a kind of memory for its visible surroundings in ACO algorithms. This inspiration from nature is used to find the rotor position without relying on the availability of prior global information.

\section{Enhanced Method}

In the new optimization method presented in this paper, the selections at the beginning and during the first tour for each ant are random. Since ants cannot evaluate distance without having previous data and do not have the ability to see the food source, the amount of pheromones is somewhat deceiving. Consequently, this cannot be the best path. In this situation the optimization method may reach an early convergence and have a suboptimum response.

In this enhanced algorithm a memory is assumed for the agents after the next iteration. Each agent analyzes the passed paths considering the available memory, and finds the best path by its calculation of $\eta$.

After that, it continues on the calculated path for its travel. In the next stage, when it has reached local stability, all of the agents repeat their own optimized path. Also the placement of the pheromones is improved on this path. The shorter and better paths between nodes will be found by considering the amount of pheromones.

After the travel of some of the agents, the algorithm will arrive at a stable and optimized response, and by increasing the number of iterations, the convergence rises. After this step, a negative feedback is created which improves the self organization feature.

Some of the dynamic practical systems that are locationdependent and time-variant, are adaptive with this algorithm. Because of the flexibility and adaptability of this algorithm to the environment, a new optimum response will be produced according to the changed environment and the new conditions. As, agents are faced to changes like new problem based on its memory in a system and therefore looks for a new solution until it reaches the desirable stability and convergence. Also, this avoids facing a local optimum. A general procedure flowchart of the new method is depicted in Fig. 1.

\section{A. Test and Simulation results of the new method}

The new method and the conventional ACO method are used for the TSP. The simulation is based on the flowchart in the 


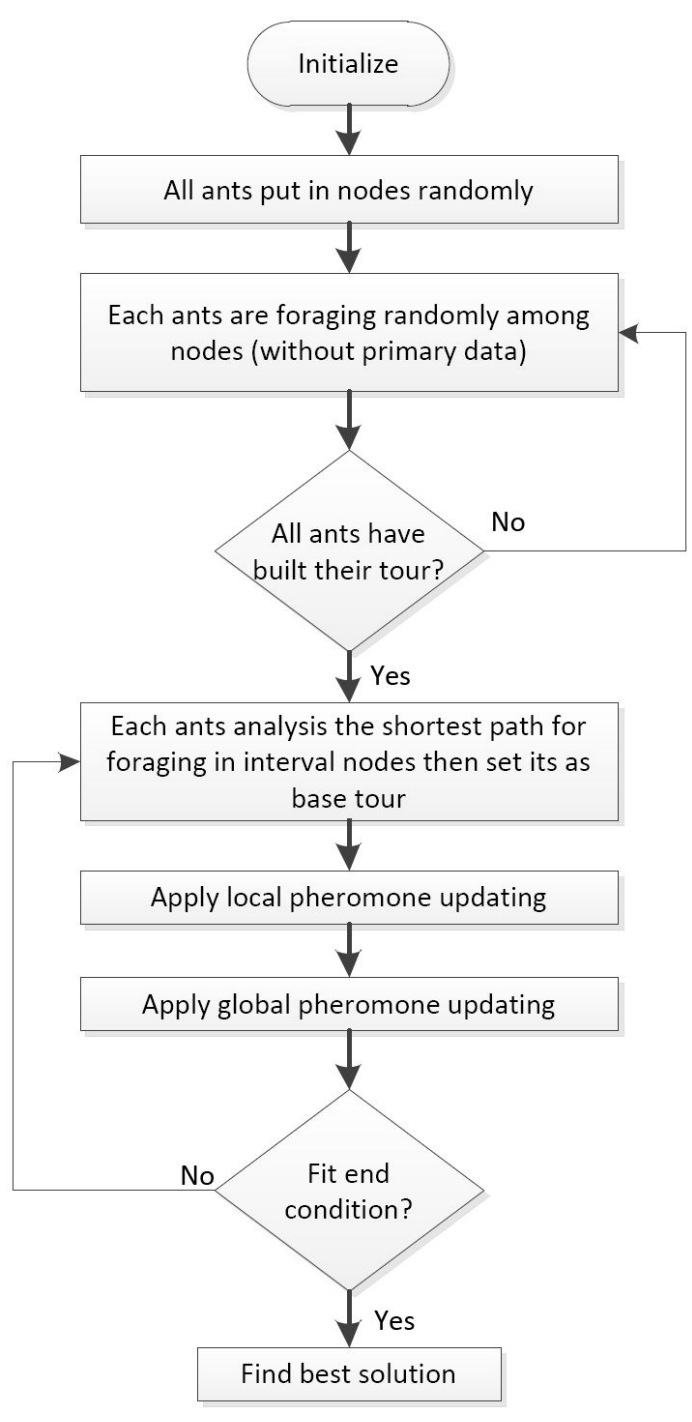

Fig. 1. The new enhanced method flowchart.

preceding section that is implemented for 100 targets in the same search space. Considering that resolving a problem using swarm intelligence is a Resultant behavior, in this method the current problem it leads to a convergence and stability proof.

In testing the model, the number of targets were the same for each method and also both of the methods were looking for the solution of the problem in similar time intervals and with an equal numbers of ants. The enhanced method reaches the shortest path in less than $85 \%$ of the time of the conventional method. In other words, the convergence in the conventional method is less than the new method and it reaches the answer more slowly and reduces the stability in accurate applications. This means that in the new method the convergence is increased by a factor of $15 \%$. Therefore, in problems where a variance of about $1 \%$ in convergence is important for optimization; it works well in ideal mode and results in a desirable stability in the time intervals.

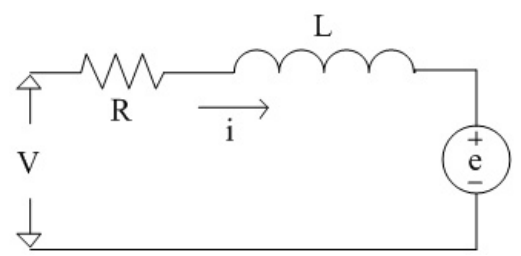

Fig. 2. Equivalent circuit for a motor phase.

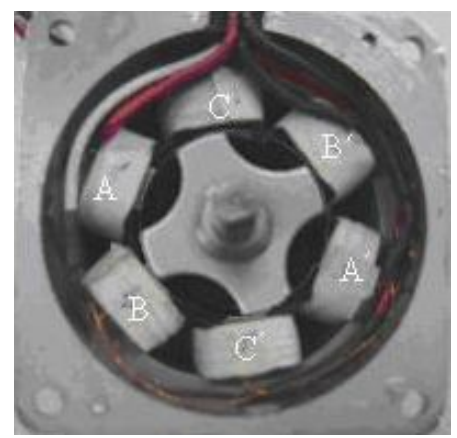

Fig. 3. The front view of $6 / 4$ switched reluctance motor.

\section{IMPLEMENTATION OF THE NEW METHOD IN ROTOR POSITION ESTIMATION}

In order to eliminate location sensors, a group of motor parameters must be used to find the rotor position. In these motors there are three quantities that are related to the rotor position; the flux linkage, the inductance and the Emf. These three quantities can be explained by using an equivalent circuit for each phase (Fig. 2) along with its relevant equation.

The following equations show the relationship between the flux, the inductance and the current:

$$
\begin{gathered}
V_{j}=R i_{j}+\frac{d}{d t} \sum_{k=1}^{m} \phi_{k j} \\
V_{j}=R i_{j}+\sum_{k=1}^{m}\left\{i_{k} \frac{\partial L_{k j}}{\partial i_{k}} \frac{d i_{k}}{d t}+L_{k j} \frac{d i_{k}}{d t}+i_{k} \frac{\partial L_{k j}}{\partial \theta} \omega\right\}
\end{gathered}
$$

where; $\phi, L, \theta$ and $\omega$ are flux linkage, the inductance, the rotor position and the angular speed, respectively. Therefore:

$$
V_{j}=R i_{j}+\frac{d}{d t} \sum_{k=1}^{m} L_{k j}\left(i_{k}, \theta\right) i_{k}
$$

Testing the active and inactive phases is done according to the flux linkage in this method. First, the 6/4 SRM depicted in Fig. 3, with the dimensions in Table I, is analyzed using the 3D Finite Element Method (FEM). Then, the SR motor is operated in different modes of operation like the healthy mode and the faulty mode. In the faulty mode; a static eccentricity fault occurs. This type of fault arises from load pressure on the shaft and displacement of its center. Under both modes of operation the flux linkage parameters from the active phases in different rotor positions is achieved.

The 6/4 three phase doubly salient SRM and its drive system, rotor position sensing block and switching angle controller implemented in this test are shown in Fig. 4. As shown in this figure, an asymmetric bridge converter is used for simplicity of the structure. Turning on the switches S1 and S2 will cause a current to flow in phase A. When the current goes up above the commanded value, S1 and S2 will turn 
TABLE I

SPECIFICATION OF THE SR MOTOR

\begin{tabular}{|c|c|}
\hline Parameter & Value \\
\hline Number of phases & 3 \\
\hline Stator core outer diameter & $72 \mathrm{~mm}$ \\
\hline Rotor core outer diameter & $40.5 \mathrm{~mm}$ \\
\hline Stack length & $36 \mathrm{~mm}$ \\
\hline Length of air gap & $0.25 \mathrm{~mm}$ \\
\hline Shaft diameter & $10 \mathrm{~mm}$ \\
\hline Rotor pole arc & $32^{\circ}$ \\
\hline Stator pole arc & $28^{\circ}$ \\
\hline Number of turns & 120 \\
\hline
\end{tabular}

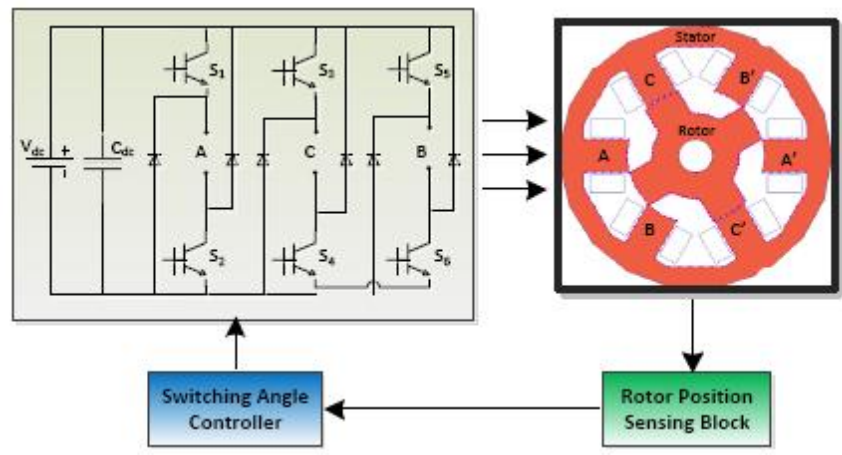

Fig. 4. SRM Drive System.

off. Then energy stored in phase A will carry the current in the same direction until it is reduced. Then, two diodes will become forward biased. Also, the proposed ACO method is implemented in a sensing block which is programmed by a microcontroller. The driver switches are communicated using a switching angle controller that is addressed by the sensing block.

On the other hand, in methods using the inactive phase, testing is done by using pulse injection into the inactive phases and extracting the essential data from the provided signals. These pulses must have a low amplitude and a high frequency in order to find the changes in the phase inductances for different angles. The initial parameters achieved at the beginning of this method are considered as the initial sources for the agents which are ants.

Agents do not have a default response to estimate position when the rotor is placed in a new position. Therefore, according to the new method the agents solve the new problem in the $[\phi]$ search space by sampling the flux linkage in the active phase and the inactive phase as below.

$$
[\phi]=\left[\phi_{a} \mid \phi_{p}\right] .
$$

In this equation, $\phi_{a}$ and $\phi_{p}$ are the flux linkage of the active and inactive phase matrixes, respectively. These search spaces and the rotor position matrix $([\boldsymbol{\theta}])$ are defined as follow:

$$
\begin{gathered}
{\left[\phi_{a}\right]_{i \times j}=\left[\begin{array}{cccc}
\phi_{a 11} & \phi_{a 12} & \cdots & \phi_{a 1 j} \\
\vdots & \vdots & & \vdots \\
\phi_{a i 1} & \phi_{a i 2} & \cdots & \phi_{a i j}
\end{array}\right]} \\
{\left[\phi_{p}\right]_{i \times j}=\left[\begin{array}{cccc}
\phi_{p 11} & \phi_{p 12} & \cdots & \phi_{p 1 j} \\
\vdots & \vdots & & \vdots \\
\phi_{p i 1} & \phi_{p i 2} & \cdots & \phi_{p i j}
\end{array}\right]} \\
{[\theta]^{T}=\left[\theta_{1}, \theta_{2}, \cdots, \theta_{i}\right] .}
\end{gathered}
$$

In these matrixes the index, $i$ represents the rotor position corresponding to $\theta$, and the index, $j$ is the different modes of motor operation in different conditions (healthy and faulty with different degrees of eccentricity). At the beginning of the new method, the agent saves the values sampled from the active and inactive phases $\left(\phi^{*}\right)$ in its own memory. Then, a new strategy is used in order to search in active and inactive phase fluxes. This leads to finding the shortest distance to the considered flux in both spaces i.e. $i, j$. Consequently, it achieves equality with the $i$ index of the rotor position matrix $([\theta])$ and finds the angle between rotor and the stator $\left(\theta_{n}\right)$. At this time, fitting the probability function is used to avoid the local optimums as follows:

$$
\begin{gathered}
\eta_{n}=\frac{1}{d_{n}}, d_{n}=\left|\phi^{*}-\phi_{i, j}\right| \\
\text { if }\left\{\begin{array}{l}
\eta_{n}>\eta_{n+1} \rightarrow i=n \\
\eta_{n}<\eta_{n+1} \rightarrow i=n+1
\end{array}\right.
\end{gathered}
$$

When the number of phases in a motor, or in other words, the number of inactive phases is increased, the flux linkage search space matrix expands to $\left[\phi_{p k}\right]_{i \times j}$, where $k$ represents the number of inactive phases. Therefore, this method can be applied to various SRM structures with any number of phases.

According to the above definition, the matrix values from the unaligned $\left(0^{\circ}\right)$ to the aligned $\left(44^{\circ}\right)$ rotor positions, according to (13), are found as follows:

$$
[\theta]^{T}=[0,4,8,12,16,20,24,28,32,36,40,44] .
$$

The value of the flux in the active phase for normal operation $(j=1)$ and the different faulty modes $(j=2,3,4,5)$ are depicted in Table II. Also, the amount of flux in the inactive phase for normal operation $(j=1)$ and the different faulty modes $(j=2,3,4,5)$ are depicted in Table III.

After implementing the new method on a motor with the same initial conditions, the optimum rotor position relative to $\phi_{i, j}^{*}$ is achieved and therefore it estimates the rotor position $\left(\theta_{i}\right)$. It can be easily seen that the flux values relative to the rotor position for each state of the motor $(j)$ have the same behavior as the initial samples of the motor.

Fitting amounts of flux linkage to estimate the rotor position in different modes of motor operation for the active and inactive phases $\left(\left[\phi_{a}^{*}\right],\left[\phi_{p}^{*}\right]\right)$, relative to $\theta$ are depicted in Table IV and Table V, respectively. These tables show that the motor's estimated behavior is the same as the main behavior of the motor. This is due to the high accuracy and the desirable algorithm behavior at different rotor angles.

In the aligned positions the motor has the maximum value of the flux linkage and in the unaligned positions it has the minimum value for the flux linkage. As the results shows, the advantage of this method over the other sensorless methods are its simplicity, increased accuracy and optimum algorithm convergence in both healthy and faulty conditions. The behavior of the SR motor is estimated with high accuracy and reliably.

$$
\left[\theta^{*}\right]^{T}=[0,4,8,12,16,20,24,28,32,36,40,44] .
$$

It has been concluded that eccentricity faults affect the flux linkage with respect to the rotor angular position characteristic. 
TABLE II

FLUX LINKAGE MATRIX IN ACTIVE PHASE FOR NORMAL AND FAULTY OPERATIONS $\left(\left[\phi_{a}\right]_{12 \times 5}\right)$

\begin{tabular}{|c|l|l|l|l|l|}
\hline Modes & $\begin{array}{l}\text { Healthy Mode } \\
j=1\end{array}$ & $\begin{array}{l}\text { Faulty Mode 1 } \\
j=2\end{array}$ & $\begin{array}{l}\text { Faulty Mode 2 } \\
j=3\end{array}$ & $\begin{array}{l}\text { Faulty Mode 3 } \\
j=4\end{array}$ & $\begin{array}{l}\text { Faulty Mode 4 } \\
j=5\end{array}$ \\
\hline$\theta_{1}$ & 7.429621151 & 7.391073264 & 7.406323647 & 7.415046575 & 7.429621151 \\
$\theta_{2}$ & 7.683246092 & 7.630201057 & 7.647775725 & 7.663943827 & 7.683246092 \\
$\theta_{3}$ & 8.399670721 & 8.298732515 & 8.324871735 & 8.368368299 & 8.399670721 \\
$\theta_{4}$ & 10.46461032 & 10.1989758 & 10.27397385 & 10.38391291 & 10.46461032 \\
$\theta_{5}$ & 17.70655652 & 16.4313513 & 16.86742026 & 17.31437283 & 17.70655652 \\
$\theta_{6}$ & 26.88032815 & 24.12093378 & 25.00402571 & 25.93325741 & 26.88032815 \\
$\theta_{7}$ & 35.4242097 & 31.66883656 & 32.91275139 & 34.1915645 & 35.4242097 \\
$\theta_{8}$ & 43.54242211 & 38.9164302 & 40.47452206 & 41.99925514 & 43.54242211 \\
$\theta_{9}$ & 50.64318094 & 45.75218759 & 47.3566289 & 49.04169217 & 50.64318094 \\
$\theta_{10}$ & 55.90542329 & 51.60524359 & 53.05643357 & 54.48014237 & 55.90542329 \\
$\theta_{11}$ & 58.97188826 & 55.42369188 & 56.63662274 & 57.82529314 & 58.97188826 \\
$\theta_{12}$ & 59.73784888 & 56.53837621 & 57.61763427 & 58.68636408 & 59.73784888 \\
\hline
\end{tabular}

TABLE III

FLUX LINKAGE MATRIX IN INACTIVE PHASE FOR NORMAL AND FAULTY OPERATIONS $\left(\left[\phi_{p}\right]_{12 \times 5}\right)$

\begin{tabular}{|c|l|l|l|l|l|}
\hline Modes & $\begin{array}{l}\text { Healthy Mode } \\
j=1\end{array}$ & $\begin{array}{l}\text { Faulty Mode } 1 \\
j=2\end{array}$ & $\begin{array}{l}\text { Faulty Mode } 2 \\
j=3\end{array}$ & $\begin{array}{l}\text { Faulty Mode } 3 \\
j=4\end{array}$ & $\begin{array}{l}\text { Faulty Mode } 4 \\
j=5\end{array}$ \\
\hline$\theta_{1}$ & 0.002091921 & 0.001827519 & 0.001895455 & 0.00199074 & 0.002091921 \\
$\theta_{2}$ & 0.001878345 & 0.001618243 & 0.001689584 & 0.001781168 & 0.001878345 \\
$\theta_{3}$ & 0.001729827 & 0.001430429 & 0.001508332 & 0.001632948 & 0.001729827 \\
$\theta_{4}$ & 0.001783767 & 0.001372431 & 0.001493309 & 0.001648652 & 0.001783767 \\
$\theta_{5}$ & 0.002655862 & 0.001621808 & 0.001985849 & 0.002345367 & 0.002655862 \\
$\theta_{6}$ & 0.003906823 & 0.00201857 & 0.002675209 & 0.003295408 & 0.003906823 \\
$\theta_{7}$ & 0.00512178 & 0.002434867 & 0.00336913 & 0.004277748 & 0.00512178 \\
$\theta_{8}$ & 0.006603802 & 0.002960593 & 0.004208851 & 0.005440929 & 0.006603802 \\
$\theta_{9}$ & 0.008397748 & 0.003634559 & 0.005223723 & 0.006851858 & 0.008397748 \\
$\theta_{10}$ & 0.010342326 & 0.004436051 & 0.006451617 & 0.008428389 & 0.010342326 \\
$\theta_{11}$ & 0.012874586 & 0.005468025 & 0.007929716 & 0.010426745 & 0.012874586 \\
$\theta_{12}$ & 0.020520543 & 0.008003463 & 0.012007388 & 0.016290402 & 0.020520543 \\
\hline
\end{tabular}

TABLE IV

FLUX LINKAGE MATRIX IN ACTIVE PHASE FOR NORMAL AND FAULTY OPERATIONS $\left(\left[\phi_{a}^{*}\right]_{12 \times 5}\right)$

\begin{tabular}{|c|l|l|l|l|l|}
\hline Modes & $\begin{array}{l}\text { Healthy Mode } \\
j=1\end{array}$ & $\begin{array}{l}\text { Faulty Mode 1 } \\
j=2\end{array}$ & $\begin{array}{l}\text { Faulty Mode } 2 \\
j=3\end{array}$ & $\begin{array}{l}\text { Faulty Mode 3 } \\
j=4\end{array}$ & $\begin{array}{l}\text { Faulty Mode 4 } \\
j=5\end{array}$ \\
\hline$\theta_{1}$ & 7.429621151 & 7.391073264 & 7.406323647 & 7.415046575 & 7.429621151 \\
$\theta_{2}$ & 7.683246092 & 7.630201057 & 7.647775725 & 7.663943827 & 7.683246092 \\
$\theta_{3}$ & 8.399670721 & 8.298732515 & 8.324871735 & 8.368368299 & 8.399670721 \\
$\theta_{4}$ & 10.46461032 & 10.1989758 & 10.27397385 & 10.38391291 & 10.46461032 \\
$\theta_{5}$ & 17.70655652 & 16.4313513 & 16.86742026 & 17.31437283 & 17.70655652 \\
$\theta_{6}$ & 26.88032815 & 24.12093378 & 25.00402571 & 25.93325741 & 26.88032815 \\
$\theta_{7}$ & 35.4242097 & 31.66883656 & 32.91275139 & 34.1915645 & 35.42420977 \\
$\theta_{8}$ & 43.54242211 & 38.9164302 & 40.47452206 & 41.99925514 & 43.54242211 \\
$\theta_{9}$ & 50.64318094 & 45.75218759 & 47.3566289 & 49.04169217 & 50.64318094 \\
$\theta_{10}$ & 55.90542329 & 51.60524359 & 53.05643357 & 54.48014237 & 55.90542329 \\
$\theta_{11}$ & 58.97188826 & 55.42369188 & 56.63662274 & 57.82529314 & 58.97188826 \\
$\theta_{12}$ & 59.73784888 & 56.53837621 & 57.61763427 & 58.68636408 & 59.73784888 \\
\hline
\end{tabular}


TABLE V

FLUX LINKAGE MATRIX IN INACTIVE PHASE FOR NORMAL AND FAULTY OPERATIONS $\left(\left[\phi_{p}^{*}\right]_{12 \times 5}\right)$

\begin{tabular}{|c|l|l|l|l|l|}
\hline Modes & $\begin{array}{l}\text { Healthy Mode } \\
j=1\end{array}$ & $\begin{array}{l}\text { Faulty Mode } 1 \\
j=2\end{array}$ & $\begin{array}{l}\text { Faulty Mode } 2 \\
j=3\end{array}$ & $\begin{array}{l}\text { Faulty Mode } 3 \\
j=4\end{array}$ & $\begin{array}{l}\text { Faulty Mode } 4 \\
j=5\end{array}$ \\
\hline$\theta_{1}$ & 0.002091921 & 0.001827519 & 0.001895455 & 0.00199074 & 0.002091921 \\
$\theta_{2}$ & 0.001878345 & 0.001618243 & 0.001689584 & 0.001781168 & 0.001878345 \\
$\theta_{3}$ & 0.001729827 & 0.001430429 & 0.001508332 & 0.001632948 & 0.001729827 \\
$\theta_{4}$ & 0.001783767 & 0.001372431 & 0.001493309 & 0.001648652 & 0.001783767 \\
$\theta_{5}$ & 0.002655862 & 0.001621808 & 0.001985849 & 0.002345367 & 0.002655862 \\
$\theta_{6}$ & 0.003906823 & 0.00201857 & 0.002675209 & 0.003295408 & 0.003906823 \\
$\theta_{7}$ & 0.00512178 & 0.002434867 & 0.00336913 & 0.004277748 & 0.00512178 \\
$\theta_{8}$ & 0.006603802 & 0.002960593 & 0.004208851 & 0.005440929 & 0.006603802 \\
$\theta_{9}$ & 0.008397748 & 0.003634559 & 0.005223723 & 0.006851858 & 0.008397748 \\
$\theta_{10}$ & 0.010342326 & 0.004436051 & 0.006451617 & 0.008428389 & 0.010342326 \\
$\theta_{11}$ & 0.012874586 & 0.005468025 & 0.007929716 & 0.010426745 & 0.012874586 \\
$\theta_{12}$ & 0.020520543 & 0.008003463 & 0.012007388 & 0.016290402 & 0.020520543 \\
\hline
\end{tabular}

Variations in this profile reduce the accuracy of the position estimation which is considered by the new method. Experiments are performed to verify the accuracy of the proposed ACO method. Fig. 5(a) and Fig. 5(b) show the test results of the position estimation and the position error with the proposed ACO method in a healthy motor at standstill. As can be seen in these figures, the two position results are almost in agreement with each other. As can be seen from Fig. 5(b), the maximum position error is 0.2 . Therefore, the rotor position in the healthy mode utilizing the new method can be estimated accurately at standstill.

The result of the estimated rotor position using the suggested method in the faulty condition is revealed and compared to the actual rotor position in Fig. 6(a) and Fig. 6(b). As demonstrated in Fig. 6, the accuracy of the initial rotor position estimation is 1.1, which is sufficient to start up a SRM without fluctuations before it can run smoothly. After that, it is expected that the difference between the estimated and actual positions be high due to the occurrence of the fault, whereas the maximum of position error is 0.7 . This shows the optimum convergence of the method.

As stated previously, the aim of this method is improved robustness when a fault appears in a SRM, which is proven from Fig. 5 and Fig. 6. On the other hand, the use of the proposed method for rotor position detection makes the control circuit isolated from the fault occurrence. Also, with this method, the rotor position can be estimated simply and without additional hardware. It also has great robustness and adaptive ability.

\section{CONCLUSION}

This paper presented a new method for the ant colony algorithm in order to estimate the rotor position in switched reluctance motors. In the new algorithm's implementation, a notable attention has been paid to the real nature of ants. This means that when first facing the problem; it does not have any initial data. These exchanges enable a flexible allocation of the work force in the foraging area in response to environmental cues. It has been seen from the testing of this method on the

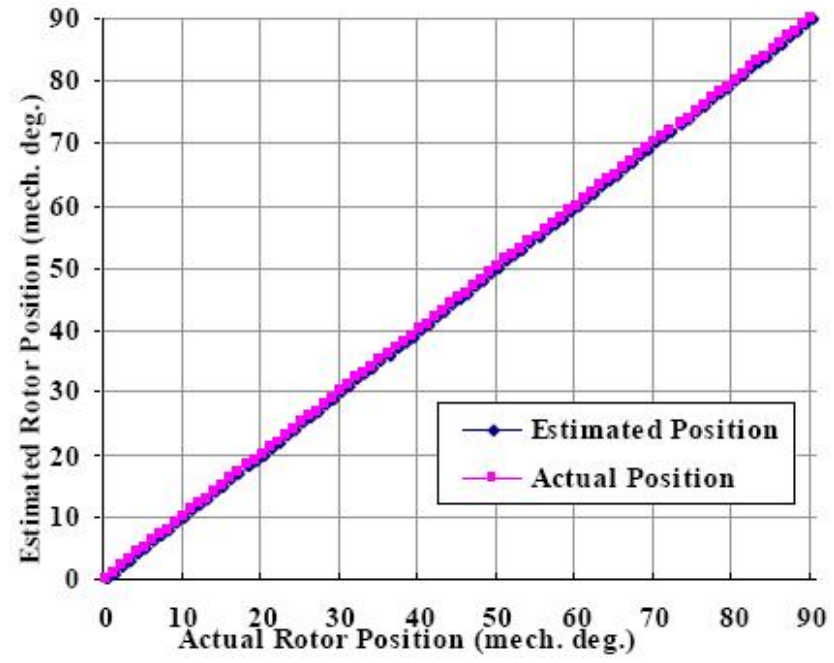

(a)

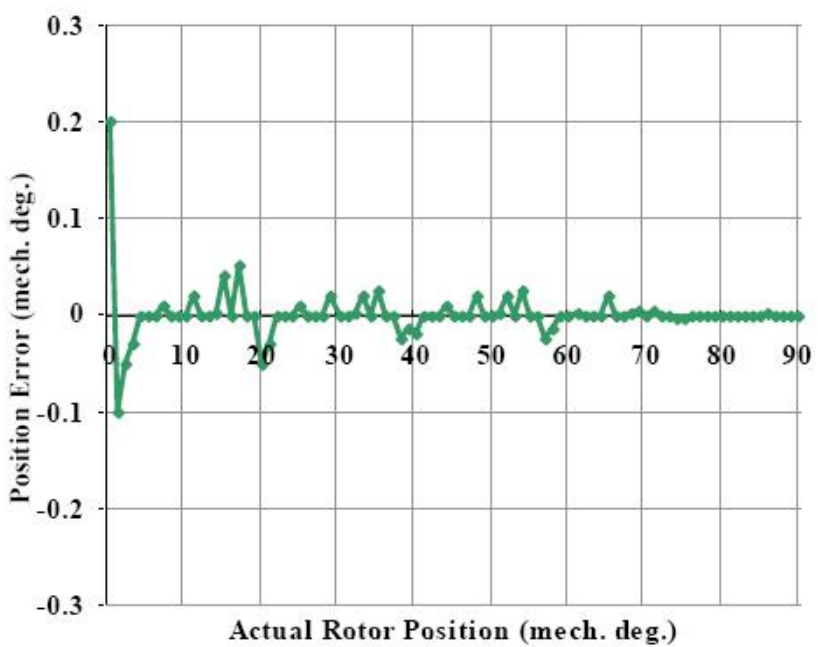

(b)

Fig. 5. Rotor position estimation at standstill in healthy mode; a) Estimated versus actual rotor position, b) Position error 


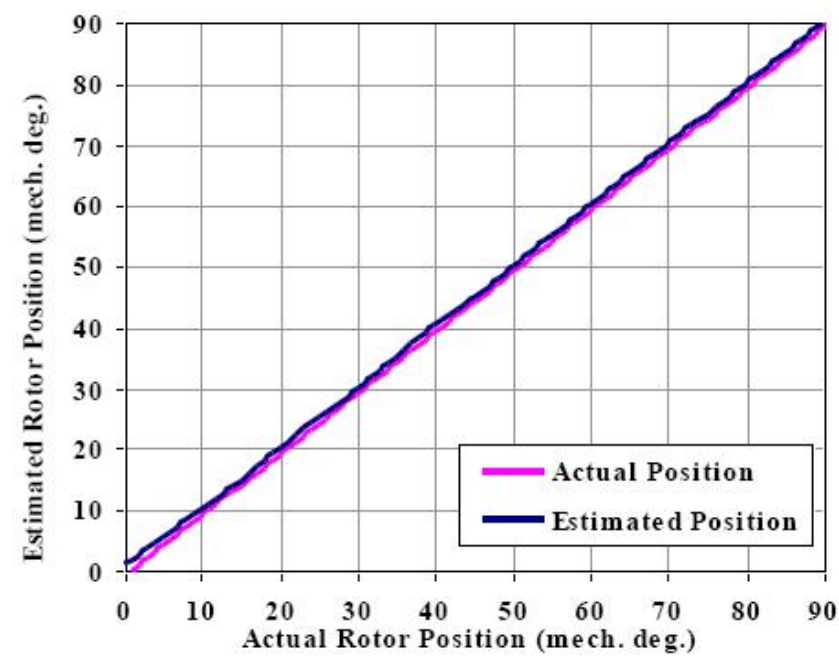

(a)

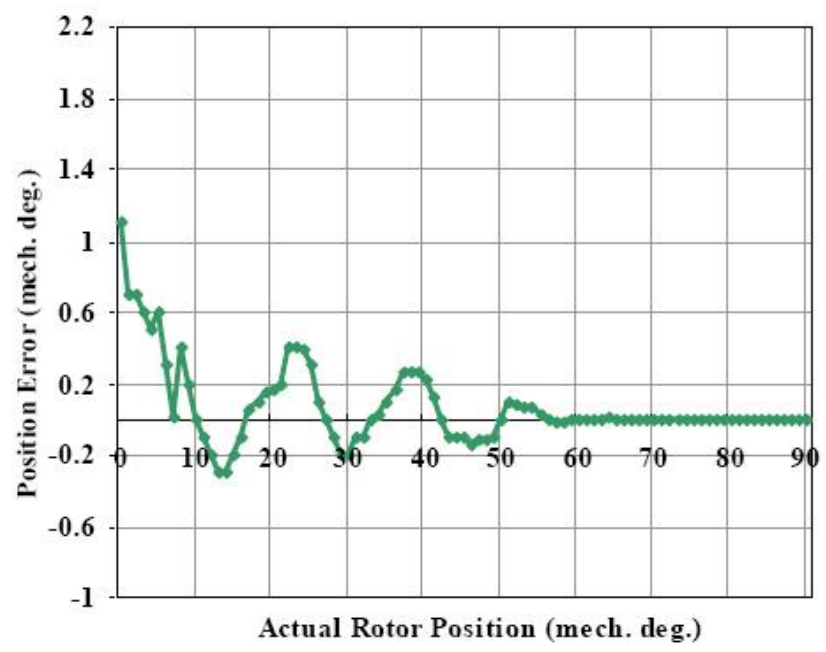

(b)

Fig. 6. Rotor position estimation at standstill in faulty mode; a) Estimated versus actual rotor position, b) Position error

TSP, and its implementation in the estimation of rotor position, that in terms of self organization and compatibility, the results exhibit greater accuracy, more desirable convergences and more stable responses in less time. Using the new method in a motor leads to sensor elimination, reduced manufacturing costs, measuring quantities reduction and the ability to use the motor in industrial environments having a lot of dust and load changes.

\section{REFERENCES}

[1] J. Kennedy, Handbook of Nature-Inspired and Innovative Computing, pp. 187-219, Swarm intelligence, 2006.

[2] M. Dorigo and T. St?tzle, Ant colony optimization, MIT Press, 2004.

[3] H. Bai and B. Zhao, "A survey on application of swarm intelligence computation to electric power system," in The Sixth World Congress on Intelligent Control and Automation, pp. 7587-7591, 2006.

[4] S. Rahmatizadeh, H. Shah-Hosseini, and H. Torkaman, "The ant-bee routing algorithm: a new agent based nature-inspired routing algorithm,' Journal of Applied Sciences, Vol. 9, No. 5, pp. 983-987, Mar. 2009.

[5] H. M. Emara, W. Elshamy, and A. Bahgat, "Parameter identification of induction motor using modified particle swarm optimization algorithm," in IEEE International Symposium on Industrial Electronics, pp. 841-847, 2008.
[6] Y.-G. Kim, H. Song, H. R. Kim, and B. Lee, "Particle swarm optimization based load model parameter identification," in IEEE Power and Energy Society General Meeting, pp. 1-6, 2010.

[7] T. Yuling, "On diagnosis prototype system for motor faults based on immune model," in International Conference on Business Intelligence and Financial Engineering, pp. 126-129, 2009.

[8] M.-K. Nguyen, Y. Jung, H.-Y. Yang, and Y.-C. Lim, "Harmonic Intensity Reduction Technique for Single Phase Switched Reluctance Motor Drives Using a New Random PWM Scheme," Journal of Power Electronics, Vol. 10, No. 1, pp. 51-57, Jan. 2010.

[9] H. Yang, D. Shin, and Y. Lim, "Sensorless control of a single-phase switched reluctance motor," Journal of Power Electronics, Vol. 9, No. 6, pp. 911-918, Nov. 2009.

[10] G. Bhuvaneswari, S. Thakurta, P. Srinivasa Rao, S. S. Murthy, "Modeling of a switched reluctance motor in sensorless and "with sensor" modes," Journal of Power Electronics, Vol. 6, No. 4, pp. 315-321, Oct. 2006.

[11] K. Ohyama, M. N. F. Nashed, K. Aso, H. Fujii, and H. Uehara, "Design using finite element analysis of a switched reluctance motor for electric vehicle," Journal of Power Electronics, Vol. 6, No. 2, pp. 163-171, Apr. 2006.

[12] H. Torkaman, M. S. Toulabi, and E. Afjei, "Electromagnetic analysis of the effects of static eccentricity fault on the radial force variations in switched reluctance motors," International Review on Modelling and Simulations, Vol. 4, No. 2, pp. 585-590, Apr. 2011.

[13] E. Afjei and H. Torkaman, "Investigation of electromagnetic characteristics in external rotor srm under dynamic eccentricity fault," International Review of Electrical Engineering, Vol. 6, No. 3, pp. 12571263, May/Jun. 2011.

[14] N. Arbab, H. Karim, H. Torkaman, E. Afjei, "New external rotor switched reluctance motor in comparison with conventional srm," International Review of Electrical Engineering, Vol. 6, No. 2, pp. 679-684, Mar./Apr. 2011.

[15] E. Afjei and H. Torkaman, "Finite element analysis of srg under fault condition oriented towards diagnosis of eccentricity fault," Applied Computational Electromagnetics Society, Vol. 26, No. 1, pp. 8-16, Jan. 2011.

[16] H. Torkaman and E. Afjei, "Magnetostatic field analysis and diagnosis of mixed eccentricity fault in switched reluctance motor," Electromagnetics, Taylor and Francis, Vol. 31, No. 5, pp. 368-383, Jun. 2011.

[17] H. Torkaman and E. Afjei, "Determining degrees of freedom for eccentricity fault in srm based on nonlinear static torque function," COMPEL:The International Journal for Computation and Mathematics in Electrical and Electronic Engineering, Vol. 30, No. 2, pp. 671-685, Feb. 2011.

[18] H. Torkaman, E. Afjei, R. Ravaud, G. Lemarquand, "Misalignment fault analysis and diagnosis in switched reluctance motor," International Journal of Applied Electromagnetics and Mechanics, Vol. 36, No. 3, pp. 253-265, Aug. 2011.

[19] H. Amiri, E. Afjei, and H. Torkaman, "Novel Sensorless phase modulation drive for a new field assisted switched reluctance motor," in IEEE International Conference on Electrical Machines and Systems (ICEMS), pp. 879-88, 2010..

[20] H. Amiri, E. Afjei, and H. Torkaman, "Indirect rotor position detection in a field assisted switched reluctance motor by utilizing aligned resonant frequency," in IEEE International Conference on Power and Energy (PECON), pp. 651-655, 2010.

[21] B. Fahimi, A. Emadi, and R. B. Sepe, "Four-quadrant position sensorless control in SRM drives over the entire speed range," IEEE Transactions on Power Electronics, Vol. 20, No. 1, pp. 154 -163, Jan. 2005.

[22] F. Cupertino, P. Giangrande, G. Pellegrino, L. Salvatore, "End effects in linear tubular motors and compensated position sensorless control based on pulsating voltage injection," IEEE Trans. Ind. Electron., Vol. 58, No. 2, pp. 494-502, Feb. 2011.

[23] A. D. Cheok and Z. Wang, "Fuzzy logic rotor position estimation based switched reluctance motor DSP drive with accuracy enhancement," IEEE Trans. Power Electron., Vol. 20, No. 4, pp. 908-921, Jul. 2005.

[24] I. Husain and M. Ehsani, "Rotor position sensing in switched reluctance motor drives by measuring mutually induced voltages," IEEE Trans. Ind. Appl., Vol. 30, No. 3, pp. 665-672, May 1994.

[25] M. Krishnamurthy, C. S. Edrington, and B. Fahimi, "Prediction of rotor position at standstill and rotating shaft conditions in switched reluctance machines," IEEE Trans. Power Electron., Vol. 21, No. 1, pp. 225 - 233, Jan. 2006. 
[26] S. Paramasivam, S. Vijayan, M. Vasudevan, R. Arumugam, R. Krishnan, "Real-time verification of ai based rotor position estimation techniques for a $6 / 4$ pole switched reluctance motor drive," IEEE Trans. Magn., Vol. 43, No. 7, pp. 3209 - 3222, Jul. 2007.

[27] E. Bonabeau, M. Dorigo, and G. Theraulaz, Swarm Intelligence from Natural to Artificial Systems: Oxford University Press, 1999.

[28] Z. J. Lee, "A hybrid algorithm applied to travelling salesman problem," in IEEE International Conference on Networking, Sensing and Control, pp. $237-242,2004$.

[29] P. Korosec, J. Silc, and B. Robic, "Mesh partitioning: a multilevel antcolony-optimization algorithm," in International Parallel and Distributed Processing Symposium, pp. 1-8, 2003.

[30] W. Gang, P. Qiang, G. Hong, Y. Gui, "A hybrid model for solving TSP based on artificial immune and ant colony," in International Conference on Computer Application and System Modeling, pp. 605-609, Oct. 2010.

[31] L. Wei and Z. Yuren, "An Effective Hybrid Ant Colony Algorithm for Solving the Traveling Salesman Problem," in International Conference on Intelligent Computation Technology and Automation, pp. 497 - 500, 2010.

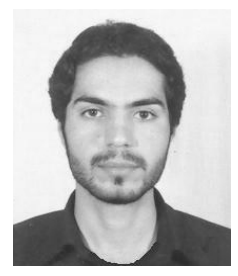

Hossein Torkaman received his M.S. and Ph.D. in Electrical Engineering from the Shahid Beheshti University, Tehran, Iran, in 2007 and 2011, respectively. He is currently with the Power Electronics, Motor Drives and Electric Machines Research Center, Electrical Engineering Department, Shahid Beheshti University, Tehran, Iran. His current research interests include numerical methods, and the modeling and diagnosis of electrical machines.

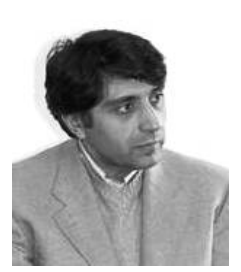

Ebrahim Afjei received his B.S. in Electrical Engineering from the University of Texas, Austin, in 1984, his M.S. in Electrical Engineering from the University of Texas at El Paso, in 1986, and his Ph.D. from New Mexico State University, Las Cruces, in 1991. He is currently a Professor in the Department of Electrical Engineering, Shahid Beheshti University, Tehran, Iran. His current research interests include electrical machines, numerical methods, and electromagnetic theory.

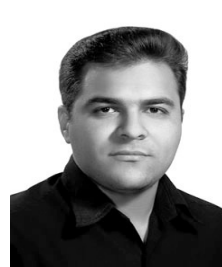

Hossein Babaee is with the Department of Electrical Engineering, Noshirvani University of Technology, Babol, Iran. He is currently a Researcher in the Power Electronics, Motor Drives and Electric Machines Research Center, Electrical Engineering Department, Shahid Beheshti University, Tehran, Iran. His current research interests include power electronics and the control of electrical machines.

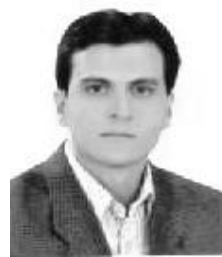

Peyman Yadegari is with the Department of Electrical Engineering, Abbaspour University of Technology, Tehran, Iran. He is currently a Researcher in the Power Electronics, Motor Drives and Electric Machines Research Center, Electrical Engineering Department, Shahid Beheshti University, Tehran, Iran. His current research interests include power electronics, and the modeling and diagnosis of electrical machines. 